illumination, the pupil size, shape, and reactions should be assessed, and the presence of blood in the anterior chamber (hyphaema) should be noted. Any visual problem or any clear sign of hyphaema or other intraocular damage (including an abnormal red reflex) should result in referral to an ophthalmologist (through the accident and emergency department) on the same day.

Indoor racquet sports are an obvious target for ocular protection as they cause an appreciable proportion of eye injuries. ${ }^{5-9}$ Improved coaching and safer play must be encouraged, yet the often quoted claim that experience alone is adequate protection has been thoroughly disproved..$^{6-10}$ Although the absolute incidence of injury is low, ${ }^{70}$ proper eye protectors are needed. Reports have established their effectiveness in other sports, ${ }^{112}$ but this message has yet to reach the squash and badminton courts. Very few players regularly wear ocular protection.

The American Society for Testing and Materials and the Canadian Standards Association have both produced an eye protector standard for squash, and increasingly in North America it is becoming compulsory to use those protectors. Unfortunately no British Standard for eye protectors exists for any sport. The numbers of squash and badminton players who wear protection in the United Kingdom is very small, not least because protectors are hard to find and vary widely in quality. It is highly unsatisfactory that protective spectacles for sport are sold with the kitemark for British Standard 2092 (industrial eye protector), which was never intended for sport. An appropriate standard is therefore necessary.

As emphasis on the benefits of sport increases participation it is important that players are sufficiently well informed about the risks of injury to protect themselves. The increasing incidence of severe eye injury in sport will, we hope, be stemmed by the improved availability of adequate ocular protection. A proper standard for eye protectors in squash and badminton is now being considered by the British Standards Institution. Its formulation will take time and is only one of the steps necessary to reduce the incidence of injury. Meanwhile, we look to the organisers of the relevant sports to recognise the existence of this problem, cooperate in educating players about the possible dangers of eye injury, and coach safer play wherever possible.

Senior Registrar in Ophthalmology,

CAROLINE J MacEWEN

Ninewells Hospital,

Dundee DD1 9SY

Lecturer in Ophthalmology,

NICHOLAS P JONES

Manchester Royal Eye Hospital,

Manchester M13 9WH

1 Garrow A. A statistical enquiry into 1000 cases of eye injuries. Br f Ophthalmol 1923;7:65-80.

2 Canavan YM, O'Flaherty MJ, Archer DB, Elwood JH. A 10-year survey of eye injuries in Northern Ireland 1967-76. Br F Ophthalmol 1980;64:618-25.

Hall NF, Denning AM, Elkington AR, Cooper PJ. The eye and the seatbelt in W'essex. Br $\mathrm{f}$ Ophthalmol 1985;69:317-9.

Cole MD, Clearkin L, Smerdon D. The seat belt law and after. Br f Ophthalmol 1987;71:36-40.

4 Cole MD, Clearkin L, Smerdon D. The seat belt law and after. Br 7 Ophthalmol 1987;71:36-40.
5 MacEwen CJ. Eye injuries: a prospective survey of 5671 cases. Br 1 Ophthalmol 1989;73:888-94.

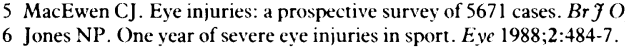

6 Jones NP. One year of severe eye injuries in sport. Eve 1988;2:484-7. incurring an eye injury. BMF 1981;283:893-5.

8 MacEwen CJ. Sport associated eye injury: a casualty department survey. $\mathrm{Br}$ J Ophthalmol 1987;71:701-5.

9 Jones NP. Eye injuries in sport: an increasing problem. Br 7 Sports Med 1987;21:168-70.

10 Clemett RS, Fairhurst SM. Head injuries from squash: a prospective study. NZ Med f 1980;92:1-3.

11 Pashby T. Eye injuries in Canadian amateur hockey. Can f Ophthalmol 1985;20:2-4.

12 Vinger $P F$. Sports eve injuries: a preventable disease. Ophthalmology 1981 :88:108-12.

\title{
The mental illness grant
}

\section{Too little, too soon}

Most of the reforms of community care listed in the NHS and Community Care Act have been postponed. But some started in April this year, although these have been overshadowed by the rows over trust hospitals and fundholding general practices.

For health authorities the most relevant of these changes are the two special discretionary grants to fund new mental health services - one for drugs and alcohol projects and one for improving the social care of people with severe mental illness. Announcing the second grant, Roger Freeman, then junior minister for health, said that it was needed because social services departments have tended to give severe mental illness low priority.

With lightning speed yet considerable thought the National Schizophrenia Fellowship has already started to evaluate the use of the grant for severe mental illness. The fellowship, a voluntary organisation that represents people with schizophrenia and their carers, welcomes the grant in principle. But it fears that the money- $£ 30 \mathrm{~m}$ a year for three years - is inadequate. Thus the fellowship's researchers set out this spring to see how and why local authorities were applying for funding.

Time was not on the side of the researchers or the local authorities: the government announced the details of the grant last September and called for bids by the end of January. In those five months local authorities had to consult users, carers, voluntary organisations, and health workers; check their plans with district health authorities and family health services authorities; and seek the blessing of regional health authorities before sending their bids to the Department of Health.

The fellowship had the same short period to contact local authorities and find out what those bids entailed. They wanted to know who would benefit from the grant. Would people stuck in psychiatry's "revolving door"-many of them with schizophrenia - be served any better? Were the proposed projects really new? The researchers chose a representative sample of 14 English local authorities to study in depth, covering a geographical, political, and financial spread. They then interviewed social services staff in the sample using a validated questionnaire and sought confirmatory data from the regional health authorities.

The good news is that some of the proposed projects should provide new kinds of informal help for severely mentally ill people. ${ }^{1}$ They include self help and drop in centres, schemes to find sympathetic landlords or landladies, and befriending (which brings together mentally ill people with volunteers prepared to commit themselves to regular visits). Although there is little research to prove that such schemes affect prognosis, it is hard to deny the feeling that low key social support is a good thing in severe mental illness. It is possible, too, but not proved, that such schemes might attract people who would be put off by more formal mental health services.

But the fellowship is worried that none of the projects are aimed specifically at people with chronically disabling mental illnesses such as schizophrenia. The remit for the grant was 
vague, and the applications for it have not detailed particular groups. And, despite some innovation, many of the bids are for services that already exist but are underfunded. One local authority applied for the grant to fund the salaries of a senior social services manager and four planning staff-hardly a direct way to improve the social care of mentally ill people. In other cases the bids are for more direct improvements such as extending the opening hours of day centres. But the government specifically stated that the money should not be used as a substitute source of funding for social care already being provided.

As the fellowship points out, this was probably wishful thinking. Local authorities have had a difficult year financially. Moreover, in the first year they have had to provide $£ 9 \mathrm{~m}$ of the $£ 30 \mathrm{~m}$ total themselves. Using the grant to augment existing services makes economic sense, particularly when capital investment has already been made and what is needed is more money for running costs. But that wasn't the intention for this grant. An attempt to help came last December, just a month before the deadline for bids. The government announced a one year scheme that allowed local authorities to borrow capital from the private sector for the new schemes that the grant would run. But for many authorities this came too late for them to rethink their plans.

So far the new mental illness grant has been only a partial success. It is a drop in the ocean for the 550000 people said to need it. Although the idea of any ring fenced money for mental health care is welcome, the grant has been introduced too hurriedly, allowing inadequate time for planning. How the grant and the other plans for community care will fare in the proposed radical reorganisation of local authorities is anybody's guess.

Assistant editor, $B M \mathcal{F}$

TRISH GROVES

1 Hogman G, Westall J. The mental illness grant: the early days. Kingston, Surrey: National Schizophrenia Fellowship, 1991.

\section{Bleeding peptic ulcers}

\section{Veni, vidi, vici per via naturalis}

Reviews on bleeding peptic ulcers that begin with comments like "the mortality is 6-10\% and has not changed over the last 30 years" are now seriously out of date. 'Better hospital care, including combined medical and surgical teams to manage acute gastrointestinal bleeding, is partly responsible, ${ }^{2}$ but the most important advances have been in endoscopic treatment. ${ }^{3}$ Few would agree with a recent comment in this journal that "endoscopic haemostasis improves results, but improvement can be achieved more simply" when the alternative is surgery. Nearly half of the deaths after upper gastrointestinal bleeds - postoperative complications and persistent bleeding - are potentially avoidable, ${ }^{5}$ and although the mortality from early surgery may be as low as $4 \%$, the price paid is the need to operate on $60 \%$ of patients. ${ }^{6}$ Few recover faster from a laparotomy than they do from an endoscopic procedure.

Doctors have long known that three out of four bleeding peptic ulcers will stop bleeding spontaneously. ${ }^{7}$ Research over the past decade has thrown light on identifying the one in four that won't. ${ }^{89}$ This relies on assessing the exact bleeding point at emergency endoscopy - if necessary by gently washing away any clot from the ulcer crater. The prognosis depends on the presence or absence of a visible vessel and whether it is bleeding. The risk of further substantial haemorrhage is at least $50 \%$ from a non-bleeding vessel and $80 \%$ if the vessel is actively bleeding; most of these cases will need further active treatment. The risk of further significant haemorrhage when there is no visible vessel is less than $10 \%$. In patients who rebleed a vessel is almost always visible if the ulcer crater is adequately visualised. ${ }^{11}$ Of non-endoscopic prognostic factors, the most important is shock on admission; the combination of shock and a visible vessel or overlying clot carries an $80 \%$ risk of further bleeding. ${ }^{12}$

A range of endoscopic therapeutic options is available, broadly divided between thermal (the most important being the neodymium yttrium aluminium garnet laser, the heater probe, and monopolar and bipolar diathermy) and injection techniques (particularly with adrenaline, ethanol, and polidocanol). Studies of their efficacy have been carried out, but the frequent failure to perform randomised, controlled studies and to identify the ulcers at high risk of further haemorrhage make the interpretation of many of them difficult.

Of six controlled trials with the neodymium yttrium aluminium garnet laser, three in which the bleeding point was not identified showed no benefit. ${ }^{13-15}$ After combining the results with those from the three studies in which the bleeding point was clearly identified the rebleeding rate was $14 \%$, the need for emergency surgery was $13 \%$, and mortality was $5 \%$ in high risk patients (those with a visible vessel) treated with the laser. The figures for the control patients were $61 \%, 52 \%$, and $23 \%$ respectively. ${ }^{11} 1617$ Comparable figures for a study using injections with adrenaline and polidocanol were $9 \%, 9 \%$, and $3 \%$ in the treatment group compared with $50 \%, 38 \%$, and $3 \%$ in controls. ${ }^{18}$ Results of trials with other thermal and injection techniques have been broadly similar, with benefit being found where high risk ulcers are identified and the bleeding point is accessible to treatment. ${ }^{19-26}$

Most of these trials used endoscopic treatment only once, and substantial rebleeding was treated by surgery. Several recent reports, however, have suggested that repeat endoscopic treatment may be effective-for example, in a study of the heater probe five of eight episodes of rebleeding were controlled by a second application. ${ }^{21}$ Yet another innovation is the combination of injection and thermal techniques. Two groups produced a considerable improvement in the efficacy of laser treatment by pre-injecting adrenaline. ${ }^{2728}$

Achieving haemostasis by endoscopy is most worth while when the results are permanent. None of the current endoscopic techniques offers any treatment of the underlying ulcer. Few long term follow up studies have been carried out after endoscopic haemostasis, but a recent report shows that the risk of further haemorrhage within two years is $9 \% .^{29}$ Almost all these episodes of rebleeding occurred within the first six months from duodenal ulcers, which had probably never healed after the index episode. This incidence is low compared with past rates-probably reflecting the recent popularity of $\mathrm{H}_{2}$ receptor antagonists. ${ }^{30}$

Most episodes of haemorrhage from peptic ulcers should now be controllable without surgery. A skilled endoscopist is 